\title{
AN IMPROVED BEAM SCREEN FOR THE LHC INJECTION KICKERS
}

\author{
M.J. Barnes, F. Caspers, L. Ducimetière, N. Garrel, T. Kroyer \\ CERN, Geneva, Switzerland
}

\begin{abstract}
The two LHC injection kicker magnet systems must produce a kick of 1.3 T.m with a flattop duration variable up to $7860 \mathrm{~ns}$, and rise and fall times of less than $900 \mathrm{~ns}$ and $3000 \mathrm{~ns}$, respectively. Each system is composed of two resonant charging power supplies (RCPSs) and four $5 \Omega$ transmission line kicker magnets with matched terminating resistors and pulse forming networks (PFNs). A beam screen is placed in the aperture of the magnets: the screen consists of a ceramic tube with conductors on the inner wall. The conductors provide a path for the image current of the, high intensity, LHC beam and screen the ferrite against Wake fields. The conductors initially used gave adequately low beam coupling impedance however inter-conductor discharges occurred during pulsing of the magnet: an alternative design was discharge free at the nominal operating voltage but the impedance was too high for the ultimate LHC beam. This paper presents the results of a new development undertaken to meet the often conflicting requirements for low beam coupling impedance, fast magnetic field risetime and good high voltage behaviour. High voltage test results and thermal measurements are also presented.
\end{abstract}

CERN, 


\title{
AN IMPROVED BEAM SCREEN FOR THE LHC INJECTION KICKERS
}

\author{
M.J. Barnes, F. Caspers, L. Ducimetière, N. Garrel, T. Kroyer, CERN, Geneva, Switzerland
}

\section{Abstract}

The two LHC injection kicker magnet systems must produce a kick of 1.3 T.m with a flattop duration variable up to $7860 \mathrm{~ns}$, and rise and fall times of less than $900 \mathrm{~ns}$ and $3000 \mathrm{~ns}$, respectively. Each system is composed of two resonant charging power supplies (RCPSs) and four $5 \Omega$ transmission line kicker magnets with matched terminating resistors and pulse forming networks (PFNs). A beam screen is placed in the aperture of the magnets: the screen consists of a ceramic tube with conductors on the inner wall. The conductors provide a path for the image current of the, high intensity, LHC beam and screen the ferrite against Wake fields. The conductors initially used gave adequately low beam coupling impedance however inter-conductor discharges occurred during pulsing of the magnet: an alternative design was discharge free at the nominal operating voltage but the impedance was too high for the ultimate LHC beam. This paper presents the results of a new development undertaken to meet the often conflicting requirements for low beam coupling impedance, fast magnetic field risetime and good high voltage behaviour. High voltage test results and thermal measurements are also presented.

\section{INTRODUCTION}

CERN, the European Laboratory for Particle Physics, is constructing the Large Hadron Collider (LHC) which will bring protons into head-on collisions at $2 \times 7 \mathrm{TeV}$ [1]. The LHC will be filled through a chain of injector machines. Two counter-rotating beams, which can collide in up to 4 interaction points, will circulate in two horizontally separated beam pipes. Each beam pipe will be filled by 12 batches of protons injected, at $450 \mathrm{GeV}$, successively on the machine circumference. Injection is carried out in the horizontal plane by a septum magnet followed by a vertical fast pulsed kicker system. Table 1 summarizes the main parameters of the LHC injection kicker system.

Table 1: LHC injection kicker system parameters [1]

\begin{tabular}{|l|r|l|}
\hline Number of magnets per system & 4 & \\
\hline Kick strength per magnet & 0.325 & T.m \\
\hline Characteristic impedance & 5 & $\Omega$ \\
\hline PFN operating voltage & 54 & $\mathrm{kV}$ \\
\hline Field flat top ripple & $< \pm 0.5$ & $\%$ \\
\hline Field flat top duration & up to 7.86 & $\mu \mathrm{s}$ \\
\hline Field rise-time $0.5 \%$ to $99.5 \%$ & 0.9 & $\mu \mathrm{s}$ \\
\hline Field fall time $99.5 \%$ to $0.5 \%$ & 3.0 & $\mu \mathrm{s}$ \\
\hline Magnet length & 2.7 & $\mathrm{~m}$ \\
\hline
\end{tabular}

The beam to be injected approaches the kicker at an angle of $0.85 \mathrm{mrad}$, requiring a total kick of 1.3 T.m for deflection onto the central machine orbit. Reflections and flat-top ripple of the field pulse must be less than $\pm 0.5 \%$, a demanding requirement, to limit the beam emittance blow-up due to injection oscillations. The 12 batches of protons are each of either $5.84 \mu \mathrm{s}$ or $7.86 \mu \mathrm{s}$ duration, leaving 11 gaps of $0.94 \mu$ s and 1 gap of $3 \mu$ s for the kick rise and fall-time, respectively.

\section{General}

\section{KICKER MAGNET}

A low impedance $(Z=5 \Omega)$ and carefully matched high bandwidth system meets the stringent pulse response requirements. The system consists of a multi-cell PFN [2] and a multi-cell travelling wave kicker magnet [3], connected by a matched transmission line and terminated by a matched resistor. Fig. 1 gives the basic schematic.

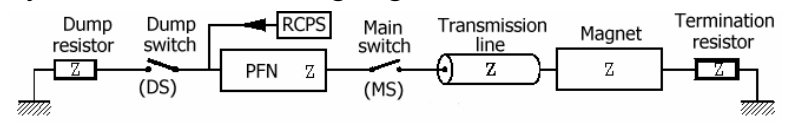

Figure 1: Schematic circuit of kicker system.

The PFN design voltage is $60 \mathrm{kV}$ and, allowing for overshoot, the magnet design voltage is $35 \mathrm{kV}$. The nominal PFN operating voltage is $54 \mathrm{kV}$.

\section{Design}

The travelling wave magnet is composed of 33 cells [2]. The nominal inductance of the ferrite C-core is $101 \mathrm{nH}$ per cell and the cell capacitance, obtained using ceramic capacitors, is $4.04 \mathrm{nF}$. The magnets are operated in vacuum of $\sim 10^{-11}$ mbar. The complete magnet is baked out at $300^{\circ} \mathrm{C}$ before $\mathrm{HV}$ conditioning and tests.

With LHC beam, which has high peak current, the impedance of the ferrite yoke can provoke significant beam induced heating, even above the Curie temperature. To limit beam coupling impedance, while allowing a fast magnetic field rise-time, a ceramic pipe with screen conductors on its inner wall is placed within the aperture of the magnet. The conductors provide a path for the image current of the beam and screen the ferrite against beam induced heating. At one end all the conductors are connected to the standard LHC vacuum chamber. At the other end all screen conductors are open circuit and were originally capacitively coupled to metallization over the last $150 \mathrm{~mm}$ of the outside diameter (OD) of the ceramic beam pipe [4]. RF fingers connect the metallization to the end faces of the vacuum tank (and thus ground). Nine ferrite toroids, referred to as Beam Impedance Reduction Ferrite (BIRF), are placed around the OD of the ceramic beam pipe at both ends. The BIRF damps high-Q resonances which the beam may otherwise excite.

In the initial design the ceramic beam pipe had 24 straight etched resistive (silver) stripes on its inner wall. These stripes gave adequately low beam impedance but, due to very high electric field at their edges, resulted in discharges between stripes during pulsing of the magnet at only $15 \mathrm{kV}$ PFN voltage. Development was carried out to rectify the discharge problem, resulting in solid conductors, each $0.7 \mathrm{~mm} \times 2.7 \mathrm{~mm}$ with radiused corners, 
inserted into slots on the inside of an extruded ceramic pipe [4]. HV tests on a magnet with 24 solid screen conductors gave no discharge until $30 \mathrm{kV}$ PFN voltage.

The highest voltage is associated with the conductors closest to the HV busbar (Fig. 2): hence, to reduce the maximum field stress by $20 \%$, the 9 conductors closest to the HV busbar were removed; this does not influence the predicted voltage on the remaining screen conductors. Subsequent testing, without any BIRF damping, was encouraging: no discharge was observed up to $49 \mathrm{kV}$ PFN voltage. However removing screen conductors has the undesirable effect of increasing beam impedance [4].

\section{BEAM SCREEN}

\section{Ferrite Heating}

Beam impedance measurements have previously been made on the magnet, in its vacuum tank, using the one wire resonator method $[4,5]$. Power deposition in the magnet is mainly in the ferrite and is calculated from the beam coupling impedance and the spectrum of the beam, assuming a $\cos ^{2}$ bunch profile at top energy $(7 \mathrm{TeV})$, which is a pessimistic assumption. The measurements gave [4]: $2400 \mathrm{~W} / \mathrm{m}$ without a screen; $41 \mathrm{~W} / \mathrm{m}$ with 24 full-length screen conductors; $116 \mathrm{~W} / \mathrm{m}$ with only 15 fulllength screen conductors and $87 \mathrm{~W} / \mathrm{m}$ with 15 full-length and 9 short screen conductors.

Measurements have been made to assess the acceptable power deposition in the ferrite: power was dissipated in the screen conductors and PT100 sensors used to measure the temperature, on both end faces of the magnet, at steady state. A dissipation of $172 \mathrm{~W} / \mathrm{m}$ resulted in a, steady-state, temperature of $108^{\circ} \mathrm{C}$ on the magnet end faces. The magnet inductance was measured to determine whether the ferrite had passed through its Curie point: the inductance decreases above $106^{\circ} \mathrm{C}$ on the end faces.

Using the Stefan-Boltzmann Law for black body radiation, neglecting conduction and making assumptions re the proportion of $172 \mathrm{~W} / \mathrm{m}$ radiated to the ferrite $(72 \%)$, emissivity of ferrite (0.8 [6]) and stainless steel vacuum tank $(0.1$ to 0.2 [7]), etc results in reasonable agreement with the measured temperature. However the measurements were made without a bake-out jacket: an estimate of the effect of the jacket results in a decrease in the limit to $90 \mathrm{~W} / \mathrm{m}$ for beam induced ferrite heating.

\section{Induced Voltage}

The voltage on a screen conductor is mainly induced by mutual coupling with the cell inductance. Hence the induced voltage, at the open end of the screen conductor, is a positive peak (Max.) during field rise and a negative peak (Min.) during field fall: the Max. is about twice the magnitude of the Min. Fig. 2 shows the predicted Max.-Min. conductor voltage versus conductor number: conductor \#1 and \#13 are adjacent to the HV and ground busbars, respectively. The largest value of Max.-Min. voltage $(\sim 42 \mathrm{kV})$ occurs for conductor \#1. Fig. 2 also shows the predicted Max.-Min. voltage between adjacent screen conductors: the largest value $(\sim 4.2 \mathrm{kV})$ occurs between conductors \#6 \& \#7 and also between \#7 \& \#8, which are closest to the legs of the C-core ferrite.

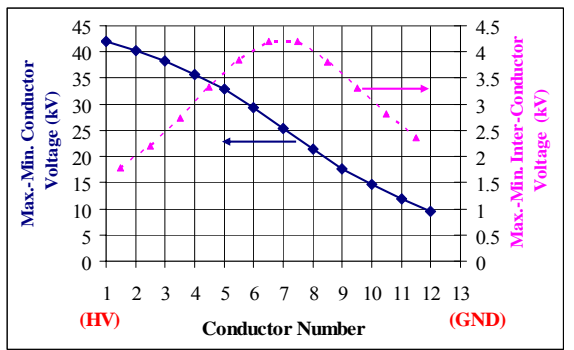

Figure 2: Predicted conductor voltage and interconductor voltage, at the open end, for 24 of solid screen conductors, for normal operation at $54 \mathrm{kV}$ PFN voltage.

\section{D Electromagnetic Model}

The capacitively coupled end of the screen conductors have been simulated using the 3D Electromagnetic Code, TOSCA. To simplify the model the ceramic tube was modelled as being flat and advantage was taken of symmetry. Each screen conductor was assigned the "Max.-Min." conductor voltage shown in Fig. 2; the metallization was modelled as being at ground potential.

The predicted maximum field gradient, from the end of screen conductor \#1, parallel to the length of the ceramic tube, is $42 \mathrm{kV} / \mathrm{mm}$. Removing the 9 screen conductors closest to the HV busbar (see above) reduces the maximum predicted field gradient to $27.3 \mathrm{kV} / \mathrm{mm}(35 \%$ reduction): this configuration has been successfully tested at $54 \mathrm{kV}$ PFN. However, removing the 9 screen conductors increased the beam induced power deposition, in the ferrite, by a factor of $\sim 3$, to over $90 \mathrm{~W} / \mathrm{m}$ [4].

Other 3D electromagnetic simulations with 24 screen conductors predict that the maximum field gradient is reduced: (a) by $10 \%$ by increasing the OD of the ceramic from $51 \mathrm{~mm}$ to $53 \mathrm{~mm}$; (b) by an additional $15 \%$ by optimizing the length of the screen conductors, such that those at lower voltage "shade" those at higher voltage; (c) by an additional $30 \%$ by removing some metallization, on the OD of the ceramic, over the end of the screen conductors - however there is a predicted field of $25 \mathrm{kV} / \mathrm{mm}$ associated with the edge of the metallization. Alternatively the maximum field gradient is reduced to $22.5 \mathrm{kV} / \mathrm{mm}$ by removing 9 screen conductors closest to the HV busbar, and then optimizing the length of the remaining screen conductors, such that those at lower voltage "shade" those at higher voltage.

The optimum lengths of screen conductors, for limiting the maximum electric field, are such that each conductor gets progressively shorter by $3 \mathrm{~mm}$, starting at the ground busbar side (\#13) until conductor \#8. Conductors \#7, \#6, \& \#5 are $4 \mathrm{~mm}, 9 \mathrm{~mm} \& 15 \mathrm{~mm}$ shorter than \#8, respectively. The total overlap between screen conductors and metallization, over the $150 \mathrm{~mm}$ length, is chosen to give a capacitive coupling of $180 \mathrm{pF}$.

\section{Beam Coupling Impedance Measurements}

Beam coupling impedance measurements, with various beam screens, have previously been reported [4]. More 
recent measurements highlighted issues with repeatability and stability of the measurement results. The main source of these issues was determined to be due to poor electrical contact between the RF fingers that connect the screen conductors or the beam pipe metallization to the end faces of the vacuum tank. Hence cones are presently used to spread the RF fingers to ensure good electrical contact with the end faces of the vacuum tank. This modification, together with careful attention during assembly, significantly improved stability and repeatability of the measurement results. Table 2 shows the results of measurements with various screen configurations. "Contact ?", in Table 2, indicates that cones were present but, because of the RF fingers being unduly bent, the electrical contact with the vacuum tank is questionable.

Table 2: Power deposition in ferrite assuming a $\cos ^{2}$ bunch profile for the nominal LHC beam at top energy

\begin{tabular}{|l|c|c|}
\hline $\begin{array}{l}\text { Screen conductor configuration: } \\
\text { conductors are each } 0.7 \mathrm{~mm} \times 2.7 \mathrm{~mm}\end{array}$ & $\begin{array}{c}\text { Power } \\
(\mathrm{W} / \mathrm{m})\end{array}$ & $\begin{array}{c}\text { Discharge } \\
\text { Inception } \\
(\mathrm{kV})\end{array}$ \\
\hline [a] No screen & $\sim 2400$ & \\
\hline $\begin{array}{l}\text { [b] } 24 \text { full-length conductors, } 150 \mathrm{~mm} \\
\text { of metallization (no cones) }\end{array}$ & 41 & 30 \\
\hline $\begin{array}{l}\text { [c] } 24 \text { optimized-length conductors, } \\
6 \mathrm{~cm}^{2} \text { metallization removed (contact?) }\end{array}$ & 85 & $\begin{array}{c}\text { Not } \\
\text { tested }\end{array}$ \\
\hline $\begin{array}{l}\text { [d] as [c] except last 4 BIRF rings } \\
\text { removed or ID metallized }\end{array}$ & $57 / 59$ & $\begin{array}{c}\text { Not } \\
\text { tested }\end{array}$ \\
\hline $\begin{array}{l}\text { [e] } 24 \text { optimized-length conductors, } \\
34 \mathrm{~cm}^{2} \text { metallization removed }\end{array}$ & 80 & $>54$ \\
\hline $\begin{array}{l}\text { [f] As [e] except last 4 BIRF rings } \\
\text { removed }\end{array}$ & 100 & $\begin{array}{c}\text { Not } \\
\text { tested }\end{array}$ \\
\hline $\begin{array}{l}\text { [g] } 15 \text { full-length conductors, } 150 \mathrm{~mm} \\
\text { of metallization (no cones) }\end{array}$ & 116 & $\begin{array}{c}49 \& 54 \\
{[4]}\end{array}$ \\
\hline $\begin{array}{l}\text { [h] } 15 \text { graded length conductors } \# 8 \\
\text { longest), } 150 \text { mm of metallization } \\
\text { (with cones) }\end{array}$ & 60 & $>57$ \\
\hline $\begin{array}{l}\text { [i] } 15 \text { (16) graded length conductors } \\
\text { (\#12 longest), 150 mm of metallization } \\
\text { (with cones) }\end{array}$ & $\begin{array}{c}60 \\
(50)\end{array}$ & $\begin{array}{c}\text { Not yet } \\
\text { tested }\end{array}$ \\
\hline
\end{tabular}

The power deposition shown in Table 2 assumes that all the power loss is in the ferrite of the magnet. However, removing only $6 \mathrm{~cm}^{2}$ of metallization almost doubles the total power deposition: the additional deposition is probably in the BIRF. Removing or metallizing the ID of the BIRF, where the beam pipe metallization is removed, reduces the power deposition by $30 \%$.

Entries [g]-[i] in Table 2 show the power deposition in the ferrite with 9 (or 8) screen conductors removed: $116 \mathrm{~W} / \mathrm{m}$ and $60 \mathrm{~W} / \mathrm{m}(50 \mathrm{~W} / \mathrm{m})$ have been measured. The main difference between entries [g] and [h]-[i] is that $116 \mathrm{~W} / \mathrm{m}[\mathrm{g}]$ is measured without cones and $60 \mathrm{~W} / \mathrm{m}$ $(50 \mathrm{~W} / \mathrm{m}[\mathrm{i}])$ with cones. The $60 \mathrm{~W} / \mathrm{m}$ is below the estimate of a $90 \mathrm{~W} / \mathrm{m}$ limit for beam induced ferrite heating and is thus considered acceptable.

\section{Discharge Inception Voltage}

The original 24 etched stripes gave discharges between stripes at only $15 \mathrm{kV}$ PFN [4]. Solid screen conductors gave no discharge until $30 \mathrm{kV}$ PFN voltage [4].
Removing the 9 conductors closest to the HV busbar resulted in no discharge up to $54 \mathrm{kV}$ PFN voltage when the BIRFs were installed. Shortening 9 screen conductors, so they end $77 \mathrm{~mm}$ before the start of the metallization, resulted in no discharge up to $48 \mathrm{kV}$ PFN voltage [4] and, after further conditioning, the magnet was successfully tested at $57 \mathrm{kV}$ PFN: however conditioning was more problematic than for only 15 screen conductors. With $34 \mathrm{~cm}^{2}$ of metallization removed, and 24 screen conductors present, the discharge inception voltage was $54 \mathrm{kV}$ PFN, however above $54 \mathrm{kV}$ major breakdowns were encountered: in addition conditioning of the magnet was very problematic (the underlying reason is not clear and could be due to poor vacuum quality). Thus it was decided to return to the configuration with 15 full-length screen conductors, with full metallization over the $150 \mathrm{~mm}$ length, and optimize the conductor lengths to reduce the voltage gradient. With this configuration the magnet was successfully tested to $57 \mathrm{kV}$ PFN voltage.

\section{CONCLUSIONS}

As a result of the high intensity of the LHC beam a screen is necessary, in the aperture of the kicker magnets, to reduce beam coupling impedance. Induced voltages on screen conductors and distortion of the magnetic field impose serious limitations. As a compromise the present screen consists of 15 optimized length conductors inserted into slots on the inside diameter of a ceramic beam-pipe. This results in a low beam coupling impedance, fast magnetic field rise-time and a discharge free beam screen at the nominal voltage. The resulting beam induced ferrite heating, of $60 \mathrm{~W} / \mathrm{m}$ for nominal LHC beam at top energy, is considered safe as the expected temperature of the ferrite $\left(91^{\circ} \mathrm{C}\right)$ is below the Curie temperature.

\section{REFERENCES}

[1] LHC Design Report, http://ab-div.web.cern.ch/abdiv/Publications/LHC-DesignReport.html

[2] M.J. Barnes, G.D. Wait \& L. Ducimetière, "High Voltage Measurements on Nine PFNs for the LHC Injection Kicker Systems", Proc. PAC'05, Knoxville, Tennessee, May 2005, pp 3402-3404.

[3] L. Ducimetière, N. Garrel, M.J. Barnes \& G.D. Wait, "The LHC Injection Kicker Magnet", Proc. PAC'03, Portland, pp1162-1164.

[4] M.J. Barnes, F. Caspers, L. Ducimetière, N. Garrel \& T. Kroyer, "The Beam Screen for the LHC Injection Kicker Magnets”, Proc. EPAC'06, 26-30 June 2006.

[5] T. Kroyer, F. Caspers \& E. Gaxiola, "Longitudinal \& Transverse Wire Measurements for the Evaluation of Impedance Reduction Measures on the MKE Extraction Kickers", CERN AB-Note-2007-028.

[6] J.C. Fagundes, A. Batista \& P. Viarouge, "Thermal Modeling of Pot Core Magnetic Components used in High Frequency Static Converters", IEEE Trans. Magnetics, Vol. 33, No. 2, Mar. 1997, pp1710-1713.

[7] http://snap.fnal.gov/crshield/crs-mech/emissivityeoi.html 